\title{
The Oceanography Classroom Connecting with Today's Freshmen
}

BY TOM GARRISON

I love teaching the first course in oceanography for non-majors-indeed, that is my professional specialty. Some readers of this column may look upon an assignment to teach a freshman general oceanography course-especially one that fulfills a general education science requirement-as a sentence to a bleak semester of blank faces and repetitive questions. Not me! As attention spans decline and cell phones proliferate, I find I must become more inventive, be more able to explain complex ideas quickly and clearly, and exude even more patience. I gladly accept the challenge.

Any proactive captain knows that forewarned is forearmed. It comes as no surprise that many of our freshman students don't think the way we do. Some of their biases and misconceptions can be used as teaching points, however, and I have a few to share.

But before reading further, please consider that some of the ideas we now find self-evident were once new and unfamiliar to us, too. Many of us struggled when we were students in the same way our students struggle today. Newton's laws of motion may be second nature to us now, but there was a first time for us. Did you pick up Coriolis effect the first time through?

Still, even after decades of honing my explanatory skills and Job-like forbearance, I am sometimes floored by some preconceptions my undergraduate non-majors bring to their first oceanography course. Few know the true nature of science.

\section{STUDENTS AND THE NATURE OF SCIENTIFIC INQUIRY}

Our students rarely understand that science is a systematic process of asking questions about the observable world by gathering and then studying information. They mistake the information itself for science. We must make it clear that science is not a collection of numbers or things, but a process: the scientific process interprets raw information by constructing a general explanation with which the information is compatible.

I explain that theories and laws in science do not arise fully formed or all at once. Scientific thought processes are a continuing chain of questioning, testing, and matching theories to observations. A theory is strengthened if new facts support it. If not, the theory is modified or a new explanation is sought. The power of science lies in the ability of the process to operate in reverse; that is, in the use of a theory or law to make predictions and anticipate new facts to be observed.

We explain that this procedure, often called the scientific method, is an orderly process by which theories are verified or rejected. It is based on the assumption that nature "plays fair" — that the rules governing natural phenomena do not change capriciously as our powers of questioning and observing improve. We believe that the answers to our questions about nature are ultimately knowable.

There is no one "scientific method." Some researchers observe, describe, and report on some subject, and leave it to others to hypothesize. Scientists don't have one single method in common-the general method they employ is a critical attitude about being shown rather than being told, and taking a logical approach to problem solving. Explain that the process is circular-new theories and laws always suggest new questions.

The most difficult task is to show beginning oceanography students that nothing is ever proven absolutely true

Tom Garrison (tomgarrison@sbcglobal. net) is an instructor at Orange Coast College, Costa Mesa, California, USA. 
by the scientific method. Theories may change as our knowledge and powers of observation change; thus, all scientific understanding is tentative. Science is neither a democratic process nor a popularity contest. The conclusions about the natural world that we reach by the process of science may not always be comfortable, easily understood, or immediately embraced, but if those conclusions consistently match observations, they may be considered true.

You will hear: "But it's only a theory." (This usually occurs in a discussion of evolution by natural selection, or explanations of the age of Earth.) Yes, and so are explanations of electricity, magnetism, and light. Organic evolution and an ancient solar system are as well supported by data as our explanations of electricity, magnetism, and light. We are not privy to truth with a capital "T.” We do the best we can with what we can sense.

\section{LAWS OF MOTION?}

I mentioned Newtonian physics, so let's start our specifics there. A body in motion will stay in motion unless acted upon by an outside force. But ask a group of new lab students to imagine a cone sitting on a table. Have them predict the behavior of a ball that has reached the bottom of the cone along a descending spiral on its surface. Will the ball roll in a straight line away from the cone when it reaches the table? The majority will predict the spiral motion will continue on the flat, ungrooved table top — that is, the ball will roll around the cone in ever-larger circles. Don't believe me? Ask them and see. Unless this is sorted out early and often, the Coriolis effect won't gel.
Action-reaction? Blow up a balloon and let it go without tying the neck, and it shoots gratifyingly around the room. Why? They'll tell you it's the air escaping from the opening pushing against the still air in the room. You counter by telling them the forces inside the balloon are unbalanced-the air is pushing the balloon in the direction away from the opening. On hearing this explanation some students tend to look like a friendly dog looks when it hears a new sound: "Whut?"

Angular momentum? Pick the tallest oarsman or basketball player, plunk him onto a swivel chair, and give him a spin. Have him expand and then contract his arms and legs. Stunned disbelief accompanies his changing rotation speed! Is he somehow cheating by touching the floor? No? Well, how does that work? Fix that before you talk about vorticity or Laplace's dynamic theory of tides.

Orbits? How can the space station stay up there, or the moon, or anything in orbit. One of my favorite teaching hitting Earth a few hundred miles from the mountain top. The third track shows the projectile heading off into space. But the second track (assisted by the precise amount of hypothetical gunpowder) shows the projectile falling toward Earth as Earth curves away. The perfect balance between gravity and inertia has been achieved-the cannonball "falls" around Earth. They love this! Lots of these same diagrams will be drawn that night on napkins at home.

\section{CHEMISTRY?}

A shampoo with "no chemicals" is something the health-conscious student might want. One wonders what might be in the bottle-a perfect vacuum? Maybe "no synthetic chemicals" is what the student has in mind. The fact that some synthetic soaps clean better and more gently, and won't leave residual films, might be overlooked. My favorite is the term "all natural," which is usually used as a sure guarantee of purity and safety. The fact that the astonishingly effective toxin in

\section{...please consider that some of the ideas we now find self-evident were once new and unfamiliar to us, too. Many of us struggled when we were students in the}

same way our students struggle today.

moments is to reproduce the diagram derived from Newton's Principia that explains the situation vividly. You know the one-it shows an impossibly high mountain jutting high above Earth. Three arcs represent the hypothetical track of three projectiles fired from a huge cannon mounted atop the mountain. The first track shows the projectile the puffer fishes admired by some Japanese gourmets, or the violent neurotoxin generated by Clostridium botulinum, are "all natural" seems to be overlooked.

How about "no preservatives?" Tell your students that the inclusion of butylated hydroxytoluene (BHT) to prevent spoilage of packaged fats has been associated with a dramatic reduction in the 
incidence of stomach cancers in North

America and Europe.

Of course there are countless dangerous synthetic chemicals, some of which are discredited preservatives, but a know-nothing approach to chemistry benefits no one. An overview of the characteristics that make some chemicals dangerous and others safe would be in order. Yes, pH will need to be broached, as will enzyme function, but it is time well spent.

\section{GEOGRAPHY?}

Great circle routes are dependable sources of fun. I ask a student to plan a route from our college in southern California to London. He'll take you over New York or Boston every time. Now give the student a globe and some string. Watch the jaws slacken when the shortest route crosses Hudson's Bay and clips Greenland. Los Angeles to Hong Kong? No, not over Hawaii-look for the Aleutians.

The Date Line is also a treat! Earlier this week, I mentioned to a student that my son and I recently missed a Monday altogether. We left Los Angeles at 2230 on a Sunday night, and reached Hong Kong on the next Tuesday morning at 0600, 16 hours ahead of Pacific Standard Time. She wondered how "weird" it must have felt to know all the news there before it had happened here. (Admittedly an extreme example, and she caught herself immediately, but thought processes are at work in that direction!)

And never assume that students know where something is located. Cape Cod, Cape Hatteras, or Cape Town may as well be on Mars for most of my surfer clientele.

\section{STATISTICS?}

One chance in ten? In a hundred? In a hundred million? It might all seem the same. A student will drive while talking on a cell phone, but drink only bottled water for fear of dangerous chemicals in the city supply. He might smoke, but also spend time at the gym in aerobic workouts to maintain cardiovascular fitness. She might drive a long distance because everybody knows flying is really dangerous. And it is a rare student indeed who correctly predicts a 50 percent probability of heads on the next fair coin toss after the coin has already come up heads 10 straight times. Statistics and probability is a minefield of student misconception.

The concept of half life is particularly difficult to teach. If the half life of an isotope is two days, most students think nothing happens for two days, then zap, half the remaining radioactive atoms instantly decay. Any discussion of Earth's age needs this error in thinking to be fixed.

Parts-per-thousand? Cubic centimeters per liter? Converting miles to kilometers? Well...

\section{OK, WHAT TO DO?}

- We must realize and accept our students' backgrounds. They come to us as they are, with skill sets that often don't include experience with contemplative, deductive thought. Cause and effect are sometimes strangers to them. But I have always been convinced that learning something new is the only permanent pleasure-that the joy of a flash of understanding is the greatest of all academic gifts. You will need to step them through a few beautiful ideas (Coriolis effect is a fine ex- ample). Later, as their deductive abilities expand, ask them to draw parallels (does Coriolis effect work on Mars the same way it works on Earth?).

- Ask your students to apply their emerging critical thinking skills. Put them into groups to measure something (the temperature of boiling water) and ask them to explain why they have different readings on their thermometers. How will they find the "true" temperature of boiling water? Is there really a "true" temperature?

- Require your students to write. Writing purifies thinking ability and allows you (and their peers) to share in the process. Writing cements firm understanding.

- Relate new knowledge to their world. Link understanding to current events-the 26 December 2004 tsunami event comes to mind. As always in our field, history, economics, geology, and hydrodynamics are intertwined.

- Never tire of trying new ways to present information. The process is Darwinian: you will retain the explanations that work, and discard those that bomb. When you arrive back in your office after a lab or seminar, jot down the winners. File these for use next term.

Never lose confidence in your students. They will learn, vote, pay your salary, and appreciate your efforts for the rest of their lives. I've been at this for 35 years, and today was my first day of a new semester. I met 550 freshman oceanography students for the first time this morning. Some seemed momentarily lost. I could not be happier! 原 